\title{
Products and Kinetics of the Reaction of Monomeric Target Bis-(Acetylacetonato) Copper(II) with Transmetalator Bis-(Diethoxydithiophosphato) Zinc(II) in Methylene Chloride
}

\author{
Hisham A. Abo-Eldahab ${ }^{1,2}$ \\ ${ }^{1}$ Chemistry Department, Faculty of Science, Alexandria, Egypt \\ ${ }^{2}$ Umm Al-Qura University, University College, Makkah, KSA \\ Email: hdahab-41@hotmail.com
}

Received 14 April 2015; accepted 25 May 2015; published 28 May 2015

Copyright (C) 2015 by author and Scientific Research Publishing Inc. This work is licensed under the Creative Commons Attribution International License (CC BY). http://creativecommons.org/licenses/by/4.0/

(c) (i) Open Access

\begin{abstract}
Reaction of bis-(acetylacetonato) copper(II) (A) with transmetalator $\mathrm{Zn}\left((\mathrm{EtO})_{2} \mathrm{PS}_{2}\right)_{2}\left(\mathrm{~B}_{2}\right.$; Et = ethyl) in methylene chloride is a simple irreversible second-order process over a wide temperature range which is the first example of a second-order reaction of mononuclear target $A$ with a transmetalator. The plots of $k_{o b s d}$ Vs [A] are linear, meaning that there is one $A$ and one $B_{2}$ in the activated complex of the slowest reaction step. The slowest step is precursor formation on the basis that $B_{2}$ is an exceptionally weak complex. The product of the $A / B_{2}$ reaction is the strong successor complex $\mathrm{Zn}(\mathrm{acac})_{2} \cdot \mathrm{Cu}(\mathrm{ps})_{2}$. The data are compared with those for reactions of the same target (A) with S-methyle isopropylidenehydrazinecarbodithioate-carbodithioato-metal(II) complexes $\mathrm{M}(\mathrm{SN})_{2}$ $\left(\mathrm{M}=\mathrm{Ni}\left(\mathrm{C}_{1}\right)\right.$ and $\left.\mathrm{Zn}\left(\mathrm{C}_{2}\right)\right)$. The reaction is not like that of $\mathrm{A}$ with $\mathrm{Ni}\left((\mathrm{MeO})_{2} \mathrm{PS}_{2}\right)_{2}\left(\mathrm{~B}_{1} ; \mathrm{Me}=\mathrm{methyl}\right)$, because it is irreversible and also consistent with the measured lower relative thermodynamic stability of $B_{2}$ compared to $B_{1}$.
\end{abstract}

\section{Keywords}

Kinetics, Mechanism, Transmetalation, Transmetallators, Thermodynamics

\section{Introduction}

Transmetalation is the stoichiometric replacement of the metals in a polymetallic target with other metals from 
reagents called transmetalotors [1]. It is a source of many new heteropolymetallic molecules that cannot be obtained by other means [2]. The transmetalation phenomenon has mostly been applied to polynuclear copper(I) [3]-[5] and copper(II) [1] [5]-[13] targets, although it is also applicable to targets containing other transition metals [10]. The best known transmetalators are S-methyl hydrazinecarbodithioate complexes $\mathrm{M}(\mathrm{NS})_{2}$, where $\mathrm{M}$ is $\mathrm{Co}, \mathrm{Ni}, \mathrm{Cu}$ and $\mathrm{Zn}$ and NS is monoanionic S-methyl isopropylidenehydrazinecarbodithioate and S-methyl benzyllidenehydrazinecarbodithioate in reagents a and $\mathrm{b}$, respectively. Transmetalation reactions proceed under mild conditions in aprotic solvents and the heteropolymetallic products are easily separated [1] [2].

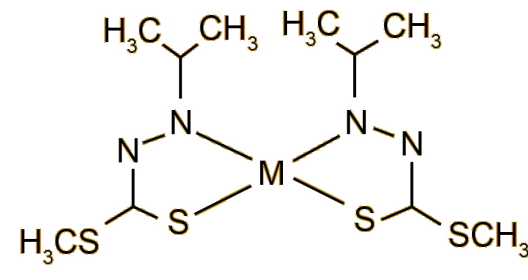

(a)

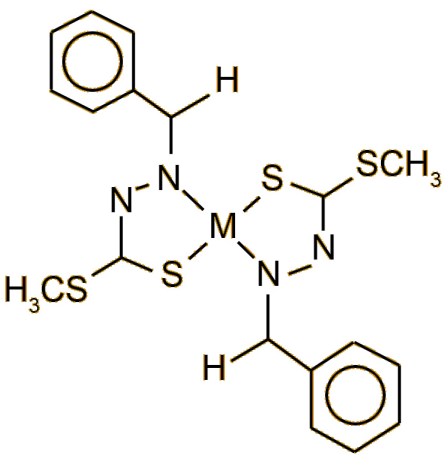

(b)

The major driving force for stoichiometric copper replacement is the formation of highly stable co-products $\mathrm{Cu}(\mathrm{NS})_{(\mathrm{S})}$ and $\mathrm{Cu}(\mathrm{NS})_{2}$ as typified by Equations (1) [5] and (2) [7], where the transmetalator is $\mathrm{A}$; $\mathrm{L}$ is an $\mathrm{N}, \mathrm{N}, \mathrm{N}$ ', $\mathrm{N}^{-}$-tetraalkyldiamine; $\mathrm{N}$ is a mohodentate pyridine ligand and $\mathrm{X}$ is $\mathrm{Cl}$ or $\mathrm{Br}$.

$$
\begin{gathered}
\mathrm{L}_{2} \mathrm{Cu}_{2} \mathrm{X}_{2}+\mathrm{M}(\mathrm{NS})_{2} \rightarrow \operatorname{LCuM}(\mathrm{NS}) \mathrm{X}_{2}+\mathrm{L}+\mathrm{Cu}(\mathrm{NS})_{(\mathrm{s})} \\
\mathrm{N}_{4} \mathrm{Cu}_{4} \mathrm{Cl}_{6} \mathrm{O}+\mathrm{xM}(\mathrm{NS})_{2} \rightarrow \mathrm{N}_{4} \mathrm{Cu}_{4} \cdot \mathrm{xM}_{x} \mathrm{Cl}_{6} \mathrm{O}+\mathrm{xCu}(\mathrm{NS})_{2}
\end{gathered}
$$

Extensive studies have shown that the patterns and specificity of progressive transmetalation reactions strongly depend on the target core structure [2].

Practical transmetalation reactions have the following characteristics:

1. The targets are easy to make and purify.

2. The reactions proceed at high rates under mild conditions in common solvents.

3. The products are in stoichiometric steps, as in Equation (3) with $\mathrm{x}=1-4$.

$$
\left(\mu_{4}-\mathrm{O}\right) \mathrm{N}_{4} \mathrm{Cu}_{4} \mathrm{CI}_{6}+\mathrm{xM}(\mathrm{NS})_{2} \rightarrow\left(\mu_{4}-\mathrm{O}\right) \mathrm{N}_{4} \mathrm{Cu}_{4} \cdot \mathrm{xM}_{x} \mathrm{CI}_{6}+\mathrm{xCu}(\mathrm{NS})_{2}
$$

4. The desired heteropolymetallic products are easy to isolate.

5. They are characterizable solids that exist as members of families containing different metals $\mathrm{M}$ in different proportions.

Transmetalation chemistry is being developed and applied in four major areas:

1. The synthesis of heteropolymetallic molecule families as a means of understanding the structures of catalytic and non-catalytic homopolymetallic targets that decomposes on attempted crystallization. We have shown that transmetalation alters the rates and rate laws of copper-catalyzed reactions [1] [14] and gives valuable information about catalyst structures [15].

2. Application of the transmetalation phenomenon to unexplored elements. This requires new labile polymetallic targets and/or transmetalators containing the elements of interest. Until recently, transmetatation chemistry was restricted to the elements Fe [5], Co [8], Ni [1] [11], Cu [10], Zn [13] [16], Cd [14], Hg [14] and Sn [14] [17], because only these elements form useful transmetalators with excellent transmetalator ligand S-methyl isopropylidenehydrazinecarbodithioate (NS) [2]. However, we have now discovered that bis-(dialkoxydithiophosphato)-metal complexes $\left((\mathrm{RO})_{2} \mathrm{PS}_{2}\right)_{\mathrm{n}} \mathrm{M}$ (abbreviated $\left.\mathrm{M}(\mathrm{PS})_{\mathrm{n}}\right)$ are transmetalators of copper targets. Application of transmetalation to new elements is likely to be successful because most of the metallic elements form dithiophosphato-complexes [18]. 
3. Thermal and electrochemical [17] [18] conversion of heteropolymetallic transmetalation products to bulk and supported metals, alloys and mixed metal oxides. The development of transmetalation chemistry thus goes hand in hand with new ways of making useful materials and catalysts.

4. Studies of transmetalation mechanisms. Transmetalation is remarkable because (a) direct transmetalation as in Equation (1) leaves the rest of the target unchanged [2] [3] [6] [7]; (b) targets react selectively with mixtures of transmetalators $\left[8_{\mathrm{b}}\right]$; and (c) different metals in a heteropolymetallic target are specifically replaced: for example, $\mathrm{Zn}(\mathrm{NS})$ specifically replaces copper in targets $\left(\mu_{4}-\mathrm{O}\right) \mathrm{N}_{4} \mathrm{Cu}_{4-\mathrm{x}} \mathrm{M}_{\mathrm{X}} \mathrm{Cl}_{6}(\mathrm{x}=1-4)$ even though replacement of $\mathrm{M}$ also is thermodynamically favorable [9] [19]. This specifically has been traced kinetically to specific interaction of the transmetalator with the metal center that is replaced [20]. The interaction occurs in precursors $\mathrm{TM} \cdot \mathrm{T}_{n}$ through Equation (4), where TM is the transmetalator; $\mathrm{T}$ is the target, $n$ is 1 or 2 and $\beta_{n}$ can range from very small [22] to moderate and measurable [22] to very large [21] [22]. It also has been found that different forms of precursors with the same stoichiometry $\mathrm{TM} \cdot \mathrm{T}$ can exist in a given system at different temperatures [20]. However, the interaction is complicated by apparent involvement of more than one metal center of a polymetallic target with the transmetalator [20].

$$
\mathrm{TM}+n \mathrm{~T}=\mathrm{TM} \cdot \mathrm{T}_{n} \quad \beta_{n}
$$

That is why we turned to bis-(acetylacetonato) copper(II) (A) as a model for the metal centers in polymetallic targets [22] [23]. Our work showed that:

1) A is capable of forming both moderately strong and very strong precursors ( $(n=1)$ Equation $(4)$ with different M(NS) $)_{\mathrm{n}}$ transmetalators) [22].

2) Different forms of TM·T precursors can be detected at different temperatures [22] [23] and the thermodynamic data can be correlated with data for precursor formation in irreversible polymetallic transmetalation systems [20]. This comparison shows that specific transmetalation occurs because:

Precursor formation is cooperative in the sense that no single property of T or TM determines the extent of precursor interaction or the rate of metal exchange [23].

3) The $\mathrm{A} / \mathrm{M}(\mathrm{NS})_{2}$ systems are reversible, which enable us to compare the thermodynamics and other properties of precursor and successor complexes [22] [23].

4) Comparison of reaction profiles for irreversible and reversible $\mathrm{A} / \mathrm{M}(\mathrm{NS})_{2}$ systems enables sub-classification of the systems according to the slow step (precursor formation thermodynamics, metal exchange kinetics and successor complex dissociation) [23].

With the promise of much new transmetalation chemistry based on $\mathrm{M}(\mathrm{PS})_{\mathrm{n}}$ tansmetalators on the horizon [18], though to provide a mechanistic comparison with established $\mathrm{M}(\mathrm{NS})_{\mathrm{n}}$ transmetalation systems by studying the products and kinetics of reaction of target $A$ with transmetalator $\left.(\mathrm{MeO})_{2} \mathrm{PS}_{2}\right)_{2} \mathrm{Ni}\left(\mathrm{B}_{1}\right)$ [24]. The results show that:

1) the $A / B_{1}$ system is reversible and involves more stable reaction precursors $A \cdot B_{1}$ than the $A / N i(N S)_{2}(A / C)$ system [22] [25];

2) different precursors $\mathrm{A} \cdot \mathrm{B}_{1}$ and different successor complexes $\mathrm{Ni}(\mathrm{acac})_{2} \cdot \mathrm{Cu}(\mathrm{PS})_{2}$ exist at different temperatures;

3) the first thermodynamic data for precursors $B_{1} \cdot A_{2}(n=2$ in Equation (2)) can be obtained;

4) precursors, activated complex and successor complex formation involve much lower entropy changes in the $A / B_{1}$ system than in the $A / C$ system.

\section{Experimental}

\subsection{Materials}

\subsubsection{Target, Solvent and Reaction Environment}

Bis-(acetylacetonato) copper(II) (A) (Alfa) was recrystallized from methylene chloride/diethylether. Methylene chloride was dried with $\mathrm{H}_{2} \mathrm{SO}_{4}$, stirred with anhydrous sodium carbonate, freshly distilled from $\mathrm{P}_{2} \mathrm{O}_{5}$ and stored in the dark over anhydrous sodium carbonate. high purity dinitrogen was deoxygenated by passage through a freshly activated column of Alfa DE-OX catalyst.

\subsubsection{Synthesis of Transmetalator, $\mathbf{B}_{2}$}

Bis(diethoxydithiophosphato) zinc(II) ( $\mathrm{Zn}(\mathrm{PS})_{2}, \mathrm{~B}_{2}$ ) was synthesized by a modified form of the literature method [2]. $B_{2}$ thermally unstable and very air sensitive. It was therefore made at low temperature from reactions 
Equations (5) and (6).

$$
\begin{gathered}
\mathrm{P}_{4} \mathrm{~S}_{10}+8 \mathrm{EtOH} \rightarrow 4\left((\mathrm{EtO})_{2} \mathrm{PS}_{2}\right) \mathrm{H}+2 \mathrm{H}_{2} \mathrm{~S} \\
2\left((\mathrm{EtO})_{2} \mathrm{PS}_{2}\right) \mathrm{H}+\mathrm{ZnCO}_{3} \rightarrow \mathrm{Zn}\left((\mathrm{EtO})_{2} \mathrm{PS}_{2}\right)_{2}\left(\mathrm{~B}_{2}\right)+\mathrm{H}_{2} \mathrm{O}+\mathrm{CO}_{2}
\end{gathered}
$$

In a typical experiment, $12.7 \mathrm{gm} \mathrm{P}_{4} 5_{10}(57.0 \mathrm{mmol})$ was placed in a $200 \mathrm{~mL}$ round-bottom flask fitted with a dinitrogen inlet, magnetic stirrer and reflux condenser. Deoxygenated anhydrous methanol $(75 \mathrm{~mL})$ was added and the mixture was refluxed under flowing dinitrogen until $\mathrm{H}_{2} \mathrm{~S}$ could no longer be detected in the effluent with lead acetate on damp filter paper (ca $45 \mathrm{~min})$. At this point, $\mathrm{ZnCO}_{3}(120 \mathrm{mmol})$ was added and the mixture was stirred under dinitrogen in the ice bath for $20 \mathrm{~min}$. Pentane $(50 \mathrm{~mL})$ was then added and, after filtration,the filtrate was then pumped to dryness in a vacuum rotary evaporator. The white solid $\mathrm{Zn}\left((\mathrm{EtO})_{2} \mathrm{PS}_{2}\right)_{2}\left(\mathrm{~B}_{2}\right)$ obtained melts sharply at $74^{\circ} \mathrm{C}$ and has a broad resonance in its ${ }^{31} \mathrm{P}$ NMR spectrum at $93.0 \mathrm{ppm}$.

\subsubsection{Physical Measurements}

Details of our procedures for product separation and analysis, kinetic measurements and data analysis can be found in the previous work [20]-[23] [26]. The relative thermodynamic stabilities of $\mathrm{Ni}(\mathrm{PS})_{2}\left(\mathrm{~B}_{1}\right), \mathrm{Zn}(\mathrm{PS})_{2}\left(\mathrm{~B}_{2}\right)$, $\mathrm{Ni}(\mathrm{NS})_{2}\left(\mathrm{C}_{1}\right)$ and $\mathrm{Zn}(\mathrm{NS})_{2}\left(\mathrm{C}_{2}\right)$ in ethanol were established by visual inspection and spectrophotometric measurements following established procedures at room temperature.

The kinetic measurements were made with a DEC PRO380 computer-assisted Hi-Tech SFL41 stopped-flow spectrophotometer over the temperature range $-25.0^{\circ} \mathrm{C}$ to $30.0^{\circ} \mathrm{C}$ controlled to $\pm 0.05^{\circ} \mathrm{C}$. The reaction of A with $B_{2}$ was monitored at $659 \mathrm{~nm}$. The concentration ranges were $[A]=2.50$ to $50.0 \mathrm{mM}$ and $\left[B_{2}\right]=0.50 \mathrm{mM}$. All experiments with transmetalator $\mathrm{Zn}(\mathrm{PS})_{2}\left(\mathrm{~B}_{2}\right)$ were conducted under dinitrogen. The concentration of A was always sufficient to ensure pseudo-first-order conditions. The pseudo-first-order rate constant $\mathrm{k}_{\text {obsd }}$ at fixed [A], [B], wavelength and temperature was obtained from the slope of a plot of $\operatorname{In}\left(A_{\infty}-A_{t}\right)$, where $A_{t}$ is the absorbance at time t. Each run was repeated at least three times to give a maximum error in each reported rate constant of $\pm 4 \%$.

\section{Results and Discussion}

\subsection{General Observation}

Practical transmetalation reactions are irreversible and stoichiometric, proceed rapidly under mild conditions and give easily separated heteropolymetallic products. These considerations require that useful transmetalation systems have a large driving force and that the reactants be kinetically labile [2]. Polynuclear copper transmetalation targets that satisfy these requirements can contain bidentate $\mathrm{N}, \mathrm{N}, \mathrm{N}^{\prime}, \mathrm{N}^{\prime}$-tetraalkylamine ligands $\mathrm{L}$, Equation (7) [5] [21]

$$
\mathrm{L}_{2} \mathrm{Cu}_{2} \mathrm{X}_{2}+\mathrm{M}(\mathrm{NS})_{2} \rightarrow \mathrm{LCuM}(\mathrm{NS}) \mathrm{X}_{2}+\mathrm{L}+\mathrm{Cu}(\mathrm{NS})_{(\mathrm{S})}
$$

and even an anionic oxo-pyridine ligand that bridges the target metal centers [3] [4] [20]. The relative stabilities of transmetalators $\mathrm{M}(\mathrm{NS})_{2}$ are useful guide to their relative reactivity's with a given target. Previous measurements show that $\mathrm{Cu}(\mathrm{NS})_{2}$ is much more thermodynamically stable than transmetalation product $\mathrm{Ni}(\mathrm{acac})_{2}$ [27].

\subsection{Reactant Structures}

Target $\mathrm{A}$ is a flat, neutral molecule [25] with only 0-donor atoms. Reactant $\mathrm{Ni}(\mathrm{PS})_{2}\left(\mathrm{~B}_{1}\right)$ is a diamagnetic, flat molecule with the $\mathrm{CH}_{3} \mathrm{O}$ groups in a plane perpendicular to the $\mathrm{N}_{\mathrm{i}} \mathrm{S}_{4}$ plane and a center of symmetry [25]. Reactant $\mathrm{Zn}(\mathrm{PS})_{2}\left(\mathrm{~B}_{2}\right)$ is a diamagnetic, flat molecule with the $\mathrm{C}_{2} \mathrm{H}_{5} \mathrm{O}$ groups in a plane perpendicular to the $\mathrm{N}_{\mathrm{i}} \mathrm{S}_{4}$ plane and a center of symmetry [25]. Transmetalator $\mathrm{Ni}(\mathrm{NS})_{2}(\mathrm{C})$ is a flattened tetrahedron (the dihedral angle is $27^{0}$ ) with a cis-geometry [28]. The reactant core structures are shown in (Figure 1).

The essential differences between reactants $\mathrm{B}$ and $\mathrm{C}$ are as follows:

1) $B$ contains four-membered rings while $C$ contains five-membered rings. Electron delocalization in the rings of $\mathrm{B}$ is indicated by high sensitivity of the ${ }^{31} \mathrm{P}$ spectrum to the identity of $\mathrm{M}$ in $\mathrm{M}(\mathrm{PS})_{2}$ [28].

2) Transmetalation requires the transfer of PS or NS ligands from the transmetalator metal to the target metal (see Equation (7)). Only M-S bonds have to be broken for this purpose in B, but the NS rings in C can, in prin- 


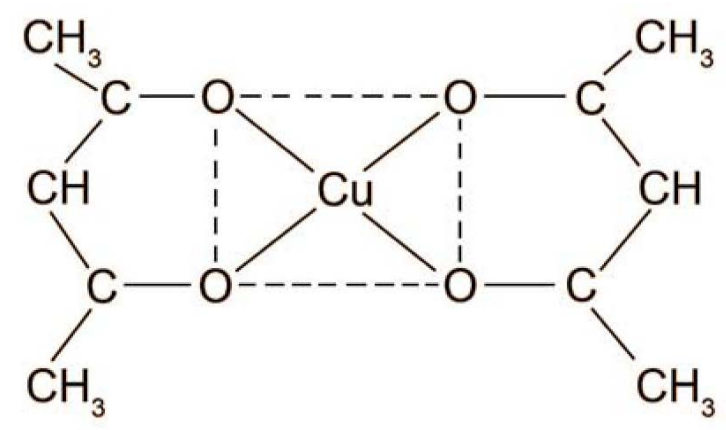

(a)

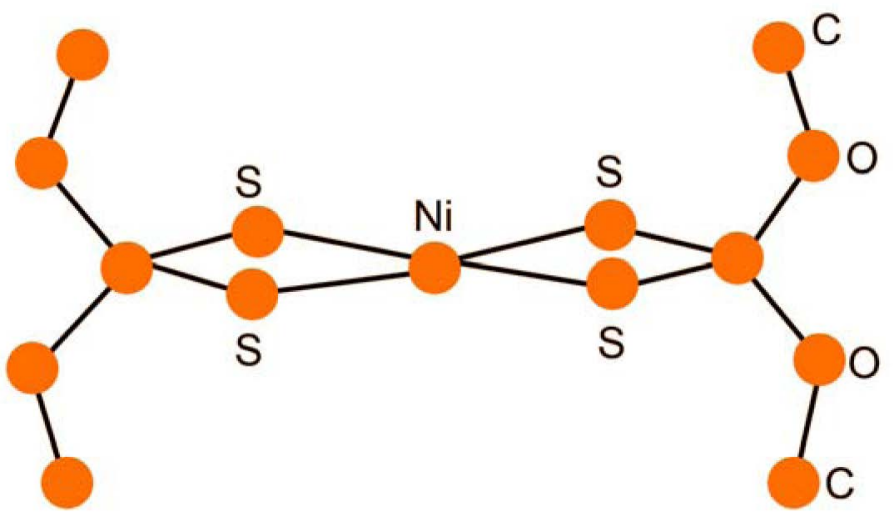

(b)

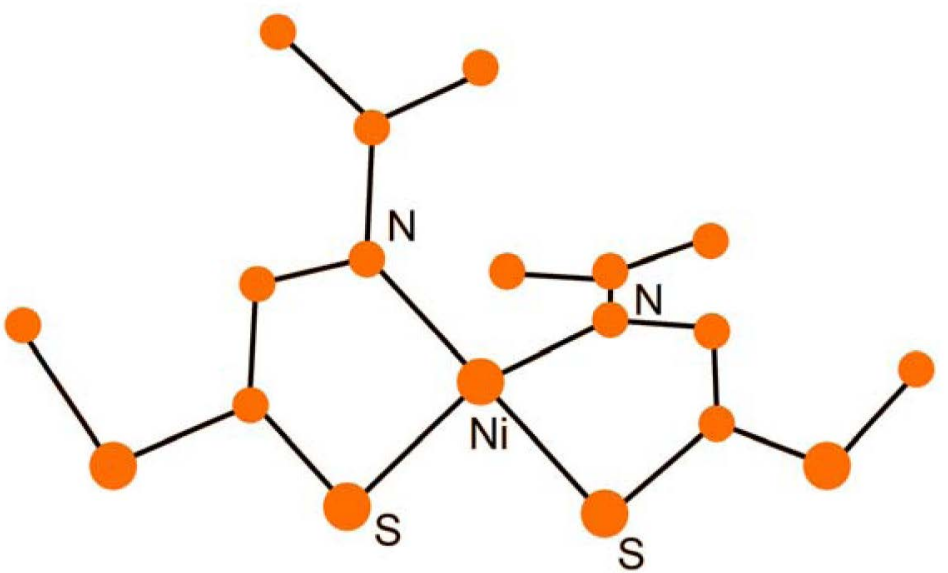

(c)

Figure 1. Core structures of target (a); reagent (b); and reagent (c).

ciple, open by Ni-N or Ni-S bond breaking.

3) Reactants B has much lower thermodynamic stability than reactant C [28].

\subsection{Transmetalation Steps}

Our current view of the sequence of steps in transmetalation reactions is based on a great deal of kinetic information [22] [23] supplemented by very recent structural insights [18]. It is summarized in Scheme 1, where X are the outermost framework atoms of the copper target, $\mathrm{M}$ is the transmetalator metal and NS is the transmetalator ligand. 


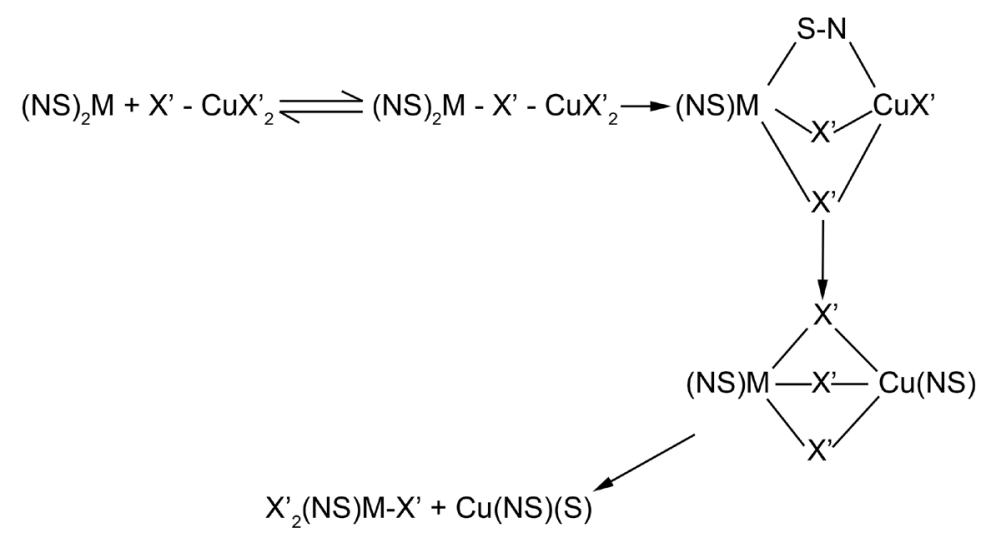

Scheme 1. The sequence of steps in transmetalation reactions.

The transmetalator metal $\mathrm{M}$ first interacts with the target atoms $\mathrm{X}$. This increases the coordination number of $\mathrm{M}$, whose NS chelate rings broken in this process and the freed $\mathrm{N}$ atoms are coordinated by the target metal center. The extent of this sharing of NS between M and the target metal determines the stoichiometry, strength and character of the precursors formed in Equation (2). The strength of $\mathrm{M}$ bonds to target $\mathrm{X}$ has now increased. The M-S bonds slowly break and the target metal chelates the transferring NS ligand. The final step is loss of $\mathrm{Cu}(\mathrm{NS})_{2}$ from the original copper(II) target. The net result of transmetalation is the replacement of target metal-X bonds with $\mathrm{M}-\mathrm{X}$ bonds.

This picture of transmetalation is supported by proof of the existence of precursor structures I and II in the reaction of $\mathrm{Sn}(\mathrm{NS})_{2} \mathrm{C1}_{2}$ with target $[\mathrm{NCuCI}]_{4}(\mathrm{~N}$ is N,N-diethylnicotinamide) and the isolation of product III from reaction of equimolar $\mathrm{Sn}(\mathrm{NS})_{4}$ with the same target [19].

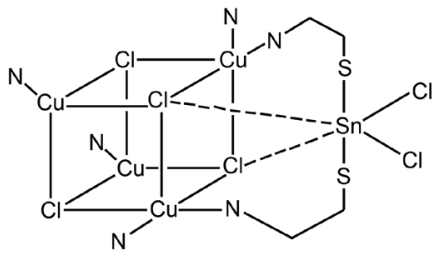

I

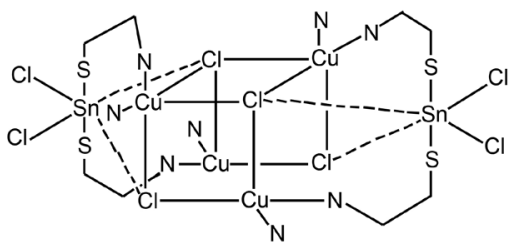

II

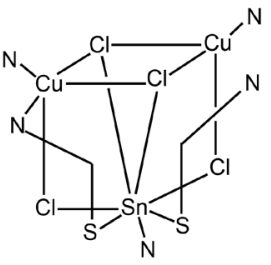

III

\subsection{Kinetics of the Reaction of $\mathrm{Cu}(\mathrm{acac})_{2},(\mathrm{~A})$ with $\mathrm{Zn}\left((\mathrm{EtO})_{2} \mathrm{PS}_{2}\right)_{2},\left(\mathrm{~B}_{2}\right)$ in Methylene Chloride}

Zinc transmetalator, $\mathrm{B}_{2}$ is much less thermodynamically stable than nickel transmetalator, $\mathrm{B}_{1}$ so we should expect $B_{2}$ to react more rapidly than $B_{1}$ with a target like $A$. This is borne out by the experimental data, which are collected in Table 1. The reaction of A with $\mathrm{B}_{2}$ is a second-order, irreversible process, as demonstrated in Figure 2. The order is the same over a wide temperature range, as demonstrated by the linear plot in Figure 3.

\subsection{Interpretation of the Data and Comparison with Other Second-Order Transmetalation Systems}

Although many polymetallic target transmetalation reactions are second-order [20] [21], this is the first example of a second-order reaction of mononuclear target A with a transmetalator. The other systems either saturate or proceed at rates which are independent of target concentration [A] [22] [23].

\subsection{There Are Two Important Characteristics of the $A / B_{2}$ System}

First, the plots of $\mathrm{k}_{\mathrm{obsd}}$ vs [A] are linear, which means that there is one $\mathrm{A}$ and one $\mathrm{B}_{2}$ in the activated complex for the slowest reaction step. At the same time, this linearity indicates that the slow step does not involve significant 


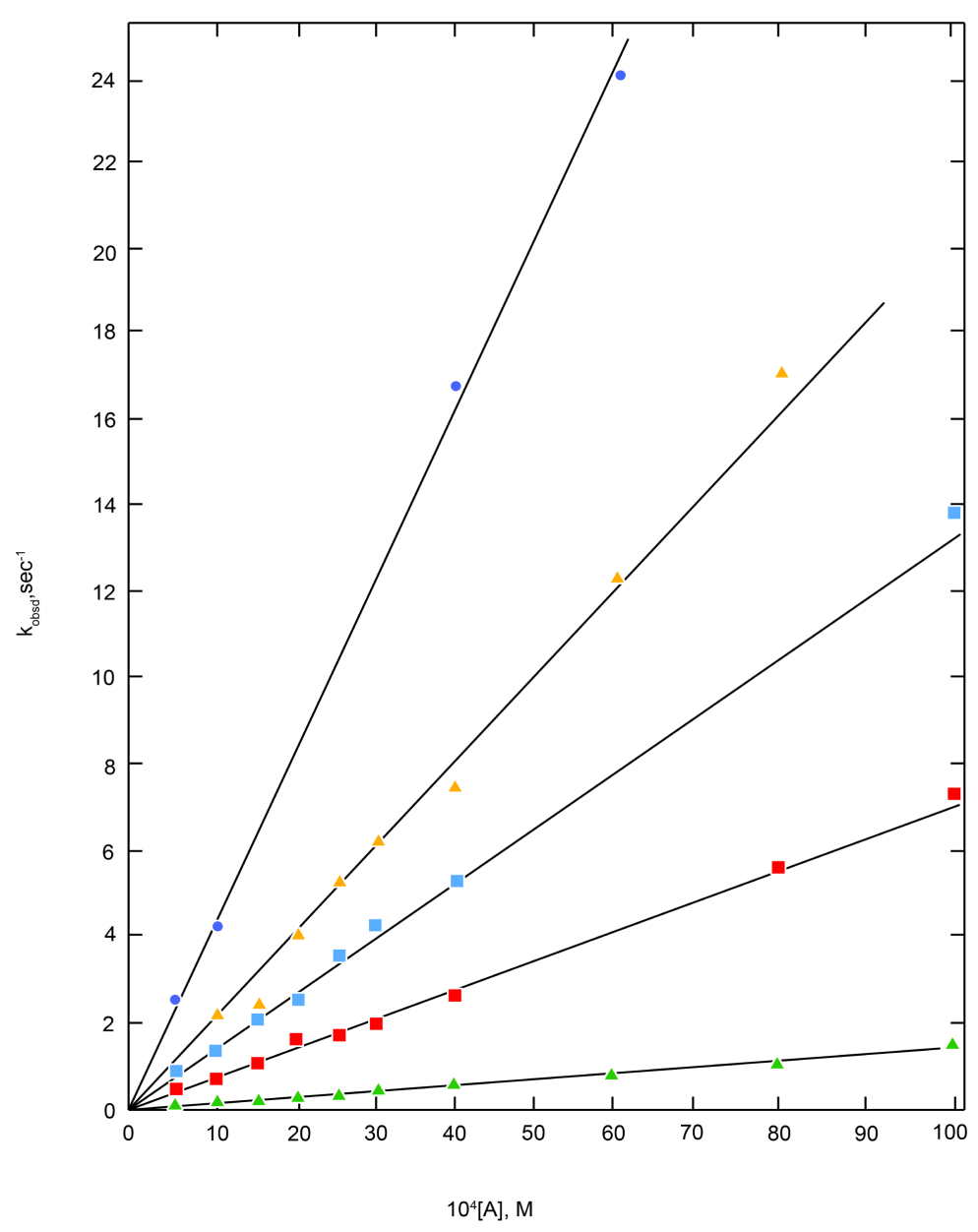

Figure 2. Plots of $\mathrm{k}_{\mathrm{obsd}}$ vs [A] for the reaction of A with $\mathrm{Zn}(\mathrm{PS})_{2} \mathrm{~B}_{2}$ in methylene chloride at the following temperatures $\left({ }^{\circ} \mathrm{C}\right)$.

Table 1. Kinetic data for the reaction of target A with $\mathrm{Zn}(\mathrm{PS})_{2}\left(\mathrm{~B}_{2}\right)$ in methylene chloride.

\begin{tabular}{cccc}
\hline Temperature & $\mathbf{1 0}^{-2} \mathbf{k}_{\mathbf{2}}, \mathbf{M}^{-\mathbf{1}} \mathbf{s e c}^{-\mathbf{1}}$ & $\mathbf{\Delta} \mathbf{H}_{2}{ }^{\# \mathbf{a}}$ & $\Delta \mathbf{S}_{2}^{\# \mathbf{b}}$ \\
-25.0 & 1.4 & & \\
-9.0 & 6.9 & $10.7 \pm 0.4$ & $5 \pm 5$ \\
0.0 & 12.6 & & \\
10.0 & 21.4 & & \\
20.0 & 39.8 &
\end{tabular}

${ }^{\mathrm{a}}$ Units are $\mathrm{kcalmol}^{-1}$; ${ }^{\mathrm{b}}$ Units are caldeg ${ }^{-1} \mathrm{~mol}^{-1}$ at $25.0^{\circ} \mathrm{C}$.

proportions of reaction precursors $A \cdot B_{2}$. Thus, the slow step is either precursor formation followed by very rapid metal exchange or slow metal exchange proceeding through a very weak precursor.

Second, the reaction is not like that of $A$ with $B_{1}$ because it is irreversible. $\mathrm{Zn}(\mathrm{PS})_{2}\left(\mathrm{~B}_{2}\right)$ is one of the very least stable $\mathrm{M}(\mathrm{PS})_{2}$ complexes, so this is not too surprising because the product of the $\mathrm{A} / \mathrm{B}_{2}$ reaction is the strong successor complex $\mathrm{Zn}(\mathrm{acac})_{2} \cdot \mathrm{Cu}(\mathrm{PS})_{2}$.

It is worth recalling 1) that $\mathrm{Zn}(\mathrm{NS})_{2}$ also is a very weak complex compared $\mathrm{To} \mathrm{Ni}(\mathrm{NS})_{2}$ and $\mathrm{Cu}(\mathrm{NS})_{2}$ [9] and 2) that it reacts with polynuclear target $\left(\mu_{4}-\mathrm{O}\right) \mathrm{N}_{4} \mathrm{Cu}\left(\mathrm{Ni}\left(\mathrm{H}_{2} \mathrm{O}\right)\right)_{3} \mathrm{Cl}_{6}$ via precursors with moderate and measurable equilibrium constants $\mathrm{B}_{1}$. By contrast, the reaction of the same target $\left(\mu_{4}-\mathrm{O}\right) \mathrm{N}_{4} \mathrm{Cu}\left(\mathrm{Ni}_{(}\left(\mathrm{H}_{2} \mathrm{O}\right)\right)_{3} \mathrm{Cl}_{6}$ with $\mathrm{Ni}(\mathrm{NS})_{2}$ is 


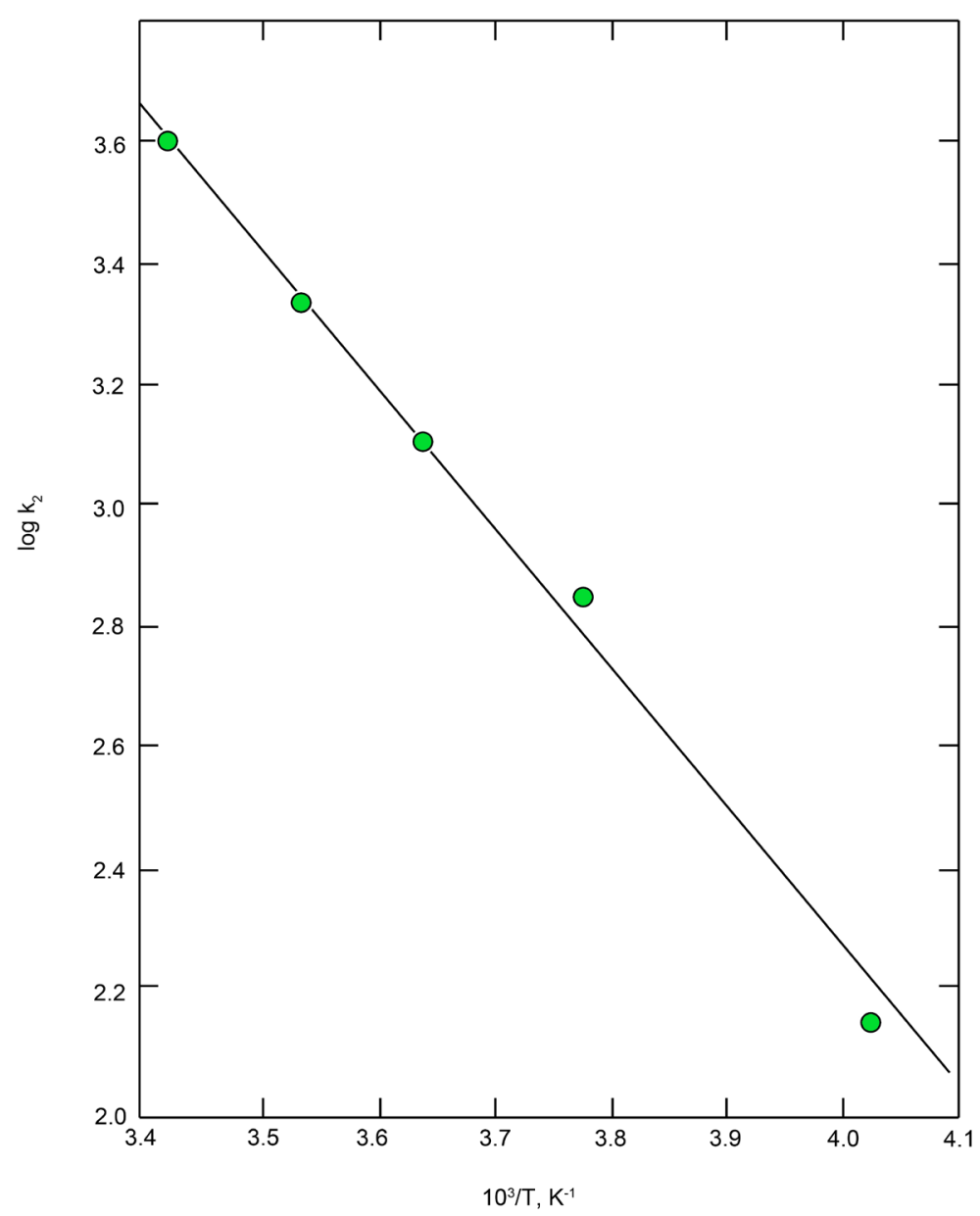

Figure 3. Plot of $\log \mathrm{k}_{2}$ vs $1 / \mathrm{T}$ for the reaction of A with $\mathrm{Zn}(\mathrm{PS})_{2} \mathrm{~B}_{2}$ in methylene chloride.

third-order and must therefore involve very weak precursors [20].

An ability of zinc transmetalators to ring-open to form more stable precursors than nickel reagents would lead us to expect either the same kind of behavior as in the reaction of $A$ with $B_{2}$ or a situation where the precursor was so stable that the reaction rate is independent of [A] [22] [23]. However, the second-order rate law for the reaction of $A$ with zinc reactant $B_{2}$ leads us strongly to suspect that the slow step is precursor formation followed by very rapid, irreversible metal exchange.

Figure 6 of Ref. [21] shows activation parameter correlations for second-order transmetalations of polynuclear copper(II) targets with reactants $\mathrm{C}$ and the corresponding S-methylbenzylidenehydrazinecarbodithioate transmetalators $\mathrm{D}$. The latter are generally more thermodynamically stable than $\mathrm{C}$ with the same $\mathrm{M}[10]$. The lowest line in that figure $\mathrm{M}$ [21] correlates six kinetic data pairs, four of which are for reactants of $\mathrm{D}(\mathrm{M}=\mathrm{Zn})$ with targets $\left(\mu_{4}-\mathrm{O}\right) \mathrm{N}_{4} \mathrm{CuX6}(\mathrm{X}=\mathrm{Cl}$ or $\mathrm{Br})$ in methylene chloride or nitrobenzene. The data pair $\left(\Delta \mathrm{H}_{2}^{\#}=10.7\right.$ $\mathrm{kcalmol}^{-1}, \Delta \mathrm{S}_{2}{ }^{\#}=5 \mathrm{cal} \mathrm{deg}^{-1} \mathrm{~mol}^{-1}$ ) for the reaction of A with $\mathrm{Zn}(\mathrm{PS})_{2}\left(\mathrm{~B}_{2}\right)$ fits this lower line. This suggests that the seven correlated data sets refer to rate-determining precursor formation in these transmetalation systems. All are irreversible and the key to this assignment is the apparent slow step in the $\mathrm{A} / \mathrm{B}_{2}$ system.

\section{Conclusion}

$\mathrm{M}(\mathrm{PS})_{2}$ complexes B is less thermodynamically stable than the corresponding $\mathrm{M}(\mathrm{NS})_{2}$ complexes $\mathrm{C}$. On this basis we might expect them to be faster transmetalators than reagents $\mathrm{M}(\mathrm{NS})_{2}$ (M common in $\mathrm{B}$ or $\mathrm{C}$ ) for a given target. Indeed, $\mathrm{Zn}(\mathrm{PS})_{2}\left(\mathrm{~B}_{2}\right)$ seems to transmetalate A via rate-determining precursor formation. However, my work shows that $\mathrm{Ni}(\mathrm{PS})_{2}\left(\mathrm{~B}_{1}\right)$ is a stronger precursor former than $\mathrm{C}_{1}$ with $\mathrm{A}$ and that this results in lower metal 
exchange rates. Nevertheless, $\mathrm{M}(\mathrm{PS})_{2}$ transmetalation systems might have even greater specificity than that having been found with S-methyl isopropylidenehydrazinecarbodithiothioate ligands [9] [20] [21] [29]. This possibility and the reactions of dithiophosphate transmetalators with other monomeric and polymetallic targets should be explored in the future work.

\section{Acknowledgements}

I would like to thank Chemistry Department Faculty of Science, Alexandria University, for support and Professor Mohamed A. El-Sayed for valuable discussions and comments.

\section{References}

[1] El-Toukhy, A., Cal, G.Z., Davies, G., Gilbert, T.R., Onan, K.D. and Veidis, M. (1984) Transmetalation Reactions of Tetranuclear Copper(II) Complexes. 2. Stoichiometry and Products of Reaction of [(DENC)CuCl $]_{4} \mathrm{O}_{2},[(\mathrm{DENC}) \mathrm{CuCl}]_{4}\left(\mathrm{CO}_{3}\right)_{2}$, $[(\mathrm{DENC}) \mathrm{CuCl}]_{4} \mathrm{Cl}_{4}$, and $(\mathrm{DENC})_{4} \mathrm{Cu}_{4} \mathrm{Cl}_{6} \mathrm{O}\left(\mathrm{DENC}=\mathrm{N}, \mathrm{N}\right.$-Diethylnicotinamide) with $\mathrm{Ni}(\mathrm{NS})_{2}$, the Kinetics of Product Isomerization in Aprotic Solvents, and Inhibition of Copper-Catalyzed Phenolic Oxidative Coupling by Dioxygen through Transmetalation. Journal of the American Chemical Society, 106, 4596-4605. http://dx.doi.org/10.1021/ja00328a050

[2] Davies, G., El-Sayed, M.A. and El-Toukhy, A. (1989) Transmetalation: A New Route to Heteropolymetallic Molecules and Materials. Comments on Inorganic Chemistry, 8, 203-220. http://dx.doi.org/10.1080/02603598908035795

[3] Cai, G.Z., Davies, G., El-Sayed, M.A., El-Toukhy, A., Gilbert, T.R., Karlin, K.D. and Zubieta, J., Eds. (1986) Biological and Inorganic Copper Chemistry, Vol. 2. Adenne, Guilderland, 237.

[4] Davies, G., El-Sayed, M.A., El-Toukhy, A., Gilbert, T.R. and Nabih, K. (1986) Transmetalation of Tetranuclear Copper Complexes. 5. Transmetalation of Copper(I) Complexes and Stoichiometry and Kinetics of Oxidation of Neutral Tetranuclear (DENC) ${ }_{3} \mathrm{Cu}_{3} \mathrm{M}(\mathrm{NS}) \mathrm{X}_{4}$ (DENC = N,N-Diethylnicotinamide) Complexes by Dioxygen in Aprotic Solvents. Inorganic Chemistry, 25, 1929-1934. http://dx.doi.org/10.1021/ic00232a004

[5] Davies, G., El-Kady, N., El-Sayed, M.A., El-Toukhy, A. and Schure, M.R. (1988) The Kinetics of Primary Events in the Reaction of $\mathrm{L}_{2} \mathrm{Cu}_{2} \mathrm{X}_{2}$ Complexes (L is an $N, N, N^{\prime} N^{\prime}$-Tetraalkyldiamine, $\mathrm{X}$ is $\mathrm{Cl}$ or $\mathrm{Br}$ ) with $\mathrm{M}(\mathrm{NS})_{2}$ Reagents. Inorganica Chimica Acta, 149, 31-43. http://dx.doi.org/10.1016/S0020-1693(00)90565-6

[6] Davies, G., El-Sayed, M.A., El-Toukhy, A., Henary, M. and Gilbert, T.R. (1986) Transmetalation of Tetranuclear Copper Complexes. 8. Transmetalation of Tetranuclear Copper(I) Complexes with a Co(NS) $)_{3}$ Reagent. Inorganic Chemistry, 25, 2373-2377. http://dx.doi.org/10.1021/ic00234a019

[7] Davies, G., El-Sayed, M.A. and El-Toukhy, A. (1986) Transmetalation of Tetranuclear Copper Complexes. 7. Spectral Evidence for the Substoichiometric Transmetalation of (.mu.4-O)[(DENC)Cu] $\mathrm{X}_{6}$ Complexes (DENC = N,N-Diethylnicotinamide; $\mathrm{X}=\mathrm{Cl}$ or $\mathrm{Br}$ ) by a Bis(Acetone S-Methyl Hydrazonecarbodithioato)Nickel Reagent. Inorganic Chemistry, 25, 2269-2271. http://dx.doi.org/10.1021/ic00233a036

[8] Henary, M., Davies, G., Abu-Raqabah, A., EI-Sayed, M.A. and El-Toukhy, A. (1988) Progressive Transmetalation of Tetranucleardioxocopper (II) Complexes with Cobalt Reagents. Inorganic Chemistry, 27, 1872.

[9] Davies, G., El-Sayed, M.A., El-Toukhy, A., Henary, M. and Martin, C.A. (1986) Distinguishable Sites in Tetranuclear Oxocopper(II) Complexes (py) $)_{3} \mathrm{Cu}_{4} \mathrm{Cl}_{4} \mathrm{O}_{2}$ and (DENC) ${ }_{3} \mathrm{Cu}_{3} \mathrm{M}\left(\mathrm{H}_{2} \mathrm{O}\right) \mathrm{Cl}_{4} \mathrm{O}_{2}(\mathrm{M}=\mathrm{Co}, \mathrm{Ni}, \mathrm{Cu}, \mathrm{Zn})$. Inorganic Chemistry, 25, 4479-4487. http://dx.doi.org/10.1021/ic00245a007

[10] Davies, G., El-Sayed, M.A., El-Toukhy, A., Henary, M., Kassem, T.S. and Martin, C.A. (1986) Selective Transmetalation and Demetalation of Heteropolynuclear Metal Complexes. Inorganic Chemistry, 25, 3904-3909. http://dx.doi.org/10.1021/ic00245a007

[11] Davies, G., El-Sayed, M.A. and El-Toukhy, A. (1986) Transmetalation of Tetranuclear Copper Complexes. 4. Structural Implications of the Kinetics of Direct Transmetalation of Tetranuclear Copper(II) Complexes by Ni(NS) ${ }_{2}$ Reagents. Inorganic Chemistry, 25, 1925-1928. http://dx.doi.org/10.1021/ic00232a003

[12] Davies, G., El-Sayed, M.A. and El-Toukhy, A. (1986) Transmetalation of Tetranuclear Copper Complexes. 9. Stoichiometry and Kinetics of Transmetalation of $\left(\mu_{4}-\mathrm{O}\right)[\mathrm{NCu}]_{4} \mathrm{X}_{6}$ Complexes by $\mathrm{M}(\mathrm{NS})_{2}$ Reagents in Aprotic Solvents. Inorganic Chemistry, 25, 3899-3903. http://dx.doi.org/10.1021/ic00242a015

[13] Abu-Raqabah, A., Davies, G., El-Sayed, M.A., El-Toukhy, A. and Henary, M. (1989) Limits of Direct Transmetalation of Polynuclear Copper(II) Complexes with $\mathrm{M}(\mathrm{NS})_{n}$ Reagents. Scissor Transmetalators. Synthesis and Properties of the Trimers $\left(\mu_{3}-\mathrm{O}\right)(\mathrm{N}, \mathrm{py})_{3} \mathrm{Cu}_{3} \mathrm{X}_{4}(\mathrm{~N}=N, N$-Diethylnicotinamide; py = Pyridine; $\mathrm{X}=\mathrm{Cl}, \mathrm{Br})$. Inorganic Chemistry, 28, 1156-1166. http://dx.doi.org/10.1021/ic00305a027

[14] El-Sayed, M.A., El-Wakil, H., Ismail, K.Z., El-Zayat, T.A. and Davies, G. (1998) Stiochiometry, Product and Kinetics of Catalytic Oxidation of 2,6-Dimethylphenol by Bromo(N,N'-Diethylenediamine)Copper Complexes in Methylene 
Chloride. Transition Metal Chemistry, 23, 795-800. http://dx.doi.org/10.1023/A:1006970209841

[15] Davies, G., El-Sayed, M.A., El-Toukhy, A. and Henary, M. (1990) Transmetalation of Tetranuclear Copper (I) Complexes with an $\mathrm{Fe}(\mathrm{NS})_{3}$ Reagent. Inorganica Chimica Acta, 168, 65-76.

[16] Davies, G., El-Toukhy, A., Veidis, M. and Onan, K.D. (1984) Transmetalation Reactions of Tetranuclear Copper(II) Complexes. I. Crystal and Molecular Structures of an Intermediate and a Final Product of Reaction of Di- $\mu$-oxo-tetra [chloro(DENC)copper(II)], (DENC = N,N-Diethylnicotinamide) with [ $\mathrm{Zn}\left(\mathrm{N}_{2} \mathrm{~S}_{2}\right)$ ], $\left(\mathrm{N}_{2} \mathrm{~S}_{2}=\right.$ Diacetylbis(hydrazonato-Smethylcarbodithioate) in Aprotic Solvents. Inorganica Chimica Acta, 84, 41-50.

[17] El-Sayed, M.A., Abu-Raqabah, A., Davies, G. and El-Toukhy, A. (1989) Kinetic Proof That the Tetranuclear Oxocopper(II) Complex (py) ${ }_{3} \mathrm{Cu}_{4} \mathrm{Cl}_{4} \mathrm{O}_{2}$ Initiates and Catalyzes the Oxidative Coupling of 2,6-Dimethylphenol by Dioxygen in Nitrobenzene. Inorganic Chemistry, 28, 1909-1914. http://dx.doi.org/10.1021/ic00309a028

[18] Mazik, J.V., Carriera, L.G. and Davies, G. (1988) Cu-Ni Alloy Formation by Reduction in Hydrogen of a Polyheterometallic Complex. Journal of Materials Science Letters, 7, 833-835. http://dx.doi.org/10.1007/BF00723777

[19] Davies, G., Giessen, B.C. and Shao, H.L. (1990) Single-Phase $\mathrm{Cu}_{0.50} \mathrm{Ni}_{0.50}$ Alloy Preparation by Thermolysis of a Simple Heteropolymetallic Precursor. Materials Letters, 9, 231-234. http://dx.doi.org/10.1016/0167-577X(90)90051-M

[20] Al-Shehri, S., Davies, G., El-Sayed, M.A. and El-Toukhy, A. (1990) Rate Law Variations in the Specific Monotransmetalation of $\left(\mu_{4}-\mathrm{O}\right)(\mathrm{N}, \mathrm{py})_{4} \mathrm{Cu}_{4-x} \mathrm{M}_{x} \mathrm{X}_{6}$ Complexes with $\mathrm{Zn}(\mathrm{NS})_{2}$ in Nitrobenzene. Inorganic Chemistry, 29, $1206-1210$.

[21] El-Sayed, M.A. and Davies, G. (1990) Stoichiometry, Products and Kinetics of Monotransmetalation and Complexation of Dimeric Complexes $\left[\mathrm{N}_{2} \mathrm{CuCl}_{2}\right]_{2}$ and $\left[\mathrm{N}_{2} \mathrm{NiCl}_{2}\right]_{2}$ (N Is $\mathrm{N}, \mathrm{N}$-Diethylnicotinamide) with $\mathrm{M}(\mathrm{NS})_{2}$ Reagents in Nitrobenzene. Inorganica Chimica Acta, 173, 163-173. http://dx.doi.org/10.1016/S0020-1693(00)80209-1

[22] Ali, A. and Davies, G. (1990) Products and Kinetics of the Reactions of Bis-(acetylacetonato)copper(II) with Ni(NS) 2 and $\mathrm{Cu}(\mathrm{NS})_{2}$ Reagents in Methylene Chloride. Inorganica Chimica Acta, 177, 167-178. http://dx.doi.org/10.1016/S0020-1693(00)85973-3

[23] Ali, A. and Davies, G. (1991) Cooperativity in Metal Exchange Reactions of Bis(acetylacetonato)copper(II) with $\mathrm{Co}(\mathrm{NS})_{2}$ and $\mathrm{Zn}(\mathrm{NS})_{2}$ Reagents in Methylene Chloride. Inorganica Chimica Acta, 179, 245-254. http://dx.doi.org/10.1016/S0020-1693(00)85884-3

[24] Zhang, C.X., Kaderli, S., Costas, M., Kim, E., Neuhold, Y.M., Karlin, K.D. and Zuberbuhler, A.D. (2003) Copper(I)-Dioxygen Reactivity of $\left[(\mathrm{L}) \mathrm{Cu}^{\mathrm{I}}\right]^{+}(\mathrm{L}=$ Tris(2-pyridylmethyl)amine): Kinetic/Thermodynamic and Spectroscopic Studies Concerning the Formation of $\mathrm{Cu}-\mathrm{O}_{2}$ and $\mathrm{Cu}_{2}-\mathrm{O}_{2}$ Adducts as a Function of Solvent Medium and 4-Pyridyl Ligand Substituent Variations. Inorganic Chemistry, 42, 1807-1824. http://dx.doi.org/10.1021/ic0205684

[25] Kastalsky, V. and MaConnel, J.F. (1969) The Crystal and Molecular Structure of Bis(dimethyldithiophosphato)nickel(II), $\mathrm{Ni}\left[\left(\mathrm{CH}_{3} \mathrm{O}\right)_{2} \mathrm{PS}_{2}\right]_{2}$. Acta Crystallographica Section B, 25, 909-915. http://dx.doi.org/10.1107/S0567740869003207

[26] El-Sayed, M.A., Abdel-Hamid, I.A., El-Zayat, T.A. and Abdel-Salam, A.H. (2006) Oxidation of Bis( $\mu$-halo)Bis[(diamine)copper(I)] Complexes [LCuX $]_{2} ; \mathrm{L}=\mathrm{TMED}, \mathrm{X}=\mathrm{Cl}$, Br or I, L = TEED or TMPD, X = Cl, with the Two Electron Organo Oxidizing Agent, Tetrachloro-1,2-Benzoquinone(TClBQ) in Aprotic Media: Models for Intermediates in Catalytic Catechol Oxidase. Transition Metal Chemistry, 31, 776-781. http://dx.doi.org/10.1007/s11243-006-0067-4

[27] Gultnokov, G. and Freiser, H. (1968) Heats and Entropies of Formation of Metal Chelates of Certain 8-Quinolonols, Quinoline-8-Thiols, and 2,4-Pentanedione. Analytical Chemistry, 40, 39-44. http://dx.doi.org/10.1021/ac60257a020

[28] Glowiak, T. and Cizsewska, T. (1978) The Crystal Structure of Bis(S-methyl-N-isopropylidendithiocarbazate)nickel(II). Inorganica Chimica Acta, 27, 27-30. http://dx.doi.org/10.1016/S0020-1693(00)87256-4

[29] Abo-El-Dahab, H.A. (2009) Kinetics and Mechanism of the Reaction of Bis-(Acetylacetonato) Copper(II) with Bis(Dithiophosphato) Nickel(II) in Methylene Chloride. Bulletin of the Faculty of Science, Alexandria University, 46, 3655. 